\title{
Relationship Between Perceived Stress, Life Satisfaction and Self Esteem Among Females Facing Domestic Violence
}

\author{
Hira Abbas ${ }^{1}$, Muhammad Waseem Shah ${ }^{2}$ \\ ${ }^{1}$ Department of Applied Pschology, Kinnard College for Women, Lahore, Pakistan \\ ${ }^{2}$ Department of Medical Research, Rehman Medical College, Peshawar, Pakistan \\ Email address: \\ humaira.abbas36@yahoo.com (H. Abbas),shah.mw87@yahoo.com (M. W. Shah)
}

\section{To cite this article:}

Hira Abbas, Muhammad Waseem Shah. Relationship Between Perceived Stress, Life Satisfaction and Self Esteem Among Females Facing Domestic Violence. Advances in Sciences and Humanities. Vol. 3, No. 5, 2017, pp. 73-75. doi: 10.11648/j.ash.20170305.15

Received: March 10, 2017; Accepted: April 5, 2017; Published: October 31, 2017

\begin{abstract}
Domestic violence against females is a very common issue In any culture, religion and ethnicity and several reasons are found to be related with it which probably cause serious health outcomes. The study was undertaken to examine the perceived stress, life satisfaction and self-esteem among females facing domestic violence. It was a correlation research study being conducted in three different centers i.e. Dar-ul-Amaan, Dastak Shelter Homes and Shaheed Benazir Bhutto Human Rights Centre for Women, Lahore Pakistan. Total sample size was 100 subjects who were selected for data collection. Purposive sampling technique was used for data collection, Perceived Stress Scale (PSS) was used for measuring mental stress level [1], Satisfaction with Life Scale (SWLS) and Rosenberg Self-esteem Scale (RSE) were used to measure a singular's emotions of self-esteem [2,3]. The data was analyzed using the Statistical Package for Social Sciences (SPSS version 18.0) by keeping 0.05 level of significance. A total of 80 subjects were approached in the study, weak negative relationship between perceived stress and life satisfaction was $\mathrm{r}(80)=-0.385, \mathrm{p}<0.001$ and our hypothesis I was accepted; A linear regression analysis revealed that perceived stress was a significant predictor of life satisfaction $(\beta=0.40, \mathrm{p}=0.008)$ accounting for $16 \%$ of the variance in life satisfaction. Concerning the relationship between perceived stress and self-esteem highlights an insignificant relationship was found; $r(80)=0.145, p=0.705$ thus Hypothesis II was rejected. Also the relationship between life satisfaction and self-esteem was not significant $\mathrm{r}(80)=0.043, \mathrm{p}=0.199$ and hypothesis III was rejected. There was considerable negative relationship observed between perceived stress and life satisfaction among females facing domestic violence, an insignificant relationship between life satisfaction and self-esteem and similarly insignificant relationship between perceived stress and self-esteem was found among females facing domestic violence.
\end{abstract}

Keywords: Domestic Violence, Stress, Self-Esteem

\section{Introduction}

The current study was intended to examine the perceived stress, life satisfaction and self-esteem among females facing domestic violence. Aggressive behavior at home against females is generally perceived general wellbeing issue over the globe. Abusive behavior at home covers a scope of physical, mental and sexual coercive acts utilized against immature and grown-up females by their husbands. Aggressive behavior at home can happen in any personal or familial relationship, regardless of whether the gatherings are living respectively or not, whether they are hitched or cohabiting or living in three-generational more distant families. It is this social component, instead of area that characterizes the brutality as 'household' [4]

Women's presentation to abusive behavior at home, in the midst of different variables, could be credited to their financial positions [5], especially in patriarchal society where they are generally impeded [6]. Financial variables interweaved with patriarchal society put the females in subordinate position, which thus have repercussions for three imperative spaces of females to be specific; the real space, 
the individual space and the subjective space. [7]

The area of this research has been chosen keeping in view the increase in domestic violence in the region where the lives of many females are affected every day to a great extent because most of the females are being abused by their partners in any manner it could be physically, psychologically and emotionally. This study will be a significant step to highlight the psychological state of the abused women so that the society could raise a voice against women abuse and should take necessary steps for the security and mental health of females facing domestic violence.

Objectives:

a To find out the relationship between perceived stress and life satisfaction among females facing domestic violence.

b To find out the relationship between perceived stress and self-esteem among females facing domestic violence.

c To find out the relationship between self-esteem and life satisfaction among females facing domestic violence.

Hypothesis

a There is a significant relationship between perceived stress and life satisfaction among females facing domestic violence

b There is a significant relationship between perceived stress and self-esteem among females facing domestic violence

c There is a significant relationship between self-esteem and life satisfaction among females facing domestic violence

\section{Materials \& Methods}

This Correlation research design was conducted in Lahore to identify the relationship between perceived stress, life satisfaction and self-esteem among females facing domestic violence, Purposive sampling technique was employed to collect the information for the research. $\mathrm{N}=80$ females facing domestic violence of all types were selected. There was no specific age range of the selected sample. The duration of the study was 06 months and sample was collected from Dar-ulAmaan (48 participants), Dastak shelter homes (17 participants), Shaheed Benazir Bhutto Human Rights Centre for Women, Lahore (15 participants).

Urdu translated versions of Perceived Stress Scale (PSS) Satisfaction with Life Scale (SWLS) and Rosenberg Selfesteem Scale were used for data collection among all subjects. Permission was obtained from the shelter homes i.e., Dar-ul-Amaan, Dastak shelter homes, Shaheed Benazir Bhutto Human Rights Centre for Women, Lahore. The participants who were approached were briefed about the nature of the research work, informed consent for the participation in research was taken from them and they were assured that their information will be kept confidential. Data was collected with the help of standardized questionnaires. Participants were given instructions about the questionnaires. Data was compiled and analyzed using SPSS version 18.0.

\section{Results}

Pearson product moment correlation coefficient was used to find the relationship between perceived stress and life satisfaction among females facing domestic violence. Concerning the relationship between perceived stress and life satisfaction highlights significant weak negative relationship between perceived stress and life satisfaction $(80)=-0.385$, $\mathrm{p}=0.001$. Thus, results indicated that there is a significant weak negative relationship between perceived stress and life satisfaction as value of $p$ is lesser than 0.05 . Thus, hypothesis is accepted (Table $1 \& 2$ )

Hypothesis I

There is a significant relationship between perceived stress and life satisfaction among females facing domestic violence.

Table 1. Pearson product moment correlation between perceived stress and life satisfaction among females facing domestic violence.

\begin{tabular}{lll}
\hline Variables & Perceived Stress & Life Satisfaction \\
\hline Perceived Stress & $-0.385^{*}$ & \\
Life Satisfaction & $-0.385^{*}$ & - \\
\hline Note: $*$ means $\mathrm{p}<0.05$ & &
\end{tabular}

A linear regression analysis revealed that perceived stress was a significant predictor of life satisfaction $(\beta=0.40, \mathrm{p}=$ 0.008 ) accounting for $16 \%$ of the variance in life satisfaction.

Table 2. Linear regression analysis for variables predicting perceived stress and life satisfaction among females facing domestic violence $(N=80)$.

\begin{tabular}{llll}
\hline Variable & $\boldsymbol{B}$ & $\boldsymbol{S E} \boldsymbol{B}$ & $\boldsymbol{\beta}$ \\
\hline Perceived stress & -0.34 & 0.1133 & $-0.384^{*}$ \\
$R^{2}$ & 0.384 & & \\
$F$ & $13.541^{*}$ & & \\
\hline Note: $\mathrm{p}<0.05^{*}$ & & &
\end{tabular}

Hypothesis II

There is a significant relationship between perceived stress and self-esteem among females facing domestic violence.

Table 3. Pearson product moment correlation between perceived stress and self-esteem among females facing domestic violence.

\begin{tabular}{lll}
\hline Variables & Self-esteem & Perceived stress \\
\hline Self-esteem & 0.145 & \\
Perceived stress & 0.145 & \\
\hline
\end{tabular}

Note: $\mathrm{p}>0.05$

Pearson product moment correlation coefficient was used to find the relationship between perceived stress and selfesteem among females facing domestic violence. Concerning the relationship between perceived stress and self-esteem highlights an in-significant relationship between perceived stress and self-esteem $\mathrm{r}(80)=0.145, \mathrm{p}=0.705$. Thus, results indicate that there is an in significant relationship between perceived stress and self-esteem as $p$ value is greater than 0.05. Thus, hypothesis is rejected.

Hypothesis III

There is a significant relationship between life satisfaction and self-esteem among females facing domestic violence. 
Table 4. Pearson product moment correlation between life satisfaction and self-esteem among females facing domestic violence.

\begin{tabular}{lll}
\hline Variables & Self-esteem & Life satisfaction \\
\hline Self-esteem & - & 0.043 \\
Life satisfaction & 0.043 & \\
\hline
\end{tabular}

Note: $\mathrm{p}>0.05$

Pearson product moment correlation coefficient was used to find the relationship between life satisfaction and selfesteem among females facing domestic violence. Concerning the relationship between life satisfaction and self-esteem highlights an in-significant relationship between life satisfaction and self-esteem $r(80)=0.043, p=0.199$. Thus, results indicated that there was an in-significant relationship between life satisfaction and self-esteem as $p$ value is greater than 0.05 . Thus, hypothesis is rejected.

\section{Discussion}

The findings of the current study shows opposite results than the previous study in which the relationship of aggressive behavior at home with life introduction, fulfillment with life, self-regard, social certainty, social nervousness and perceived stress was investigated, it showed positive and strong relationship between life fulfillment and perceived stress and abusive behavior at home essentially influences mental well being of females, especially their fulfillment with life, self- regard, and gloom scores [8]. The findings of this study shows similar results to a previous study which showed a significant weak negative relationship between perceived stress and life satisfaction in females facing domestic violence and the women who were facing spousal violence scored high on depression, perceived stress and their life satisfaction was also low. [3]

The findings of research shows opposite results than the previous study that showed positive and strong relationship between life fulfillment and self-esteem and abusive behavior at home essentially influences mental well being of females, especially their fulfillment with life, self- regard, and gloom scores [8] while our findings are supported by a previous study in which in-significant relationship between life satisfaction and self-esteem among females facing domestic violence was observed. [9]

The results of the current research are supported by a one of previous studies that found an in-significant relationship between perceived stress and self-esteem and the results also showed that depression, state nervousness is higher in females facing domestic violence than females who are not facing domestic violence. [10]

\section{Conclusion}

The results concluded that there is a significant weak negative relationship between perceived stress and life satisfaction among females facing domestic violence, while an in-significant relationship between life satisfaction and self-esteem among females facing domestic violence was found and similarly, there is an in significant relationship between perceived stress and self-esteem among females facing domestic violence.

\section{References}

[1] Cohen S. Perceived tress cale. Psychology [Internet]. 1994;13. Available from: http://www.mindgarden.com/products/pss.htm.

[2] Diener Ed, Emmons RA, Larsen RJ GS. The Satisfaction With Life Scale. 1985. p. 49(1):71-5.

[3] Rosenberg M. Society and the adolescent self-image. Princeton, NJ. 1965.

[4] García Moreno C, Jansen H, Ellsberg M, Heise L, Watts C. WHO Multi-Country Study on Women's Health and Domestic Violence Against Women. 2005.

[5] Weaver TL, Sanders CK, Campbell CL, Schnabel M. Development and preliminary psychometric evaluation of the domestic violence--related financial issues scale (DV-FI). J Interpers Violence [Internet]. 2009 Apr [cited 2016 Oct 16]; 24(4): 569-85. Available from: http://www.ncbi.nlm.nih.gov/pubmed/18445829.

[6] BARNETT OW. Why Battered Women Do Not Leave, Part 2: External Inhibiting Factors--Social Support and Internal Inhibiting Factors. Trauma, Violence, Abus [Internet]. SAGE Publications; 2001 Jan 1 [cited 2016 Oct 16]; 2(1): 3-35. Available from: http://tva.sagepub.com/cgi/doi/10.1177/152483800100200100 1.

[7] Burlae KK. The Theory of Mindful Space: Identifying, Understanding, and Preventing Violence. Affilia [Internet]. SAGE Publications; 2004 Feb 1 [cited 2016 Oct 16]; 19(1):8 5-98. Available from: http://aff.sagepub.com/cgi/doi/10.1177/0886109903260665.

[8] Hassan S, Malik AA. Psycho-social Correlates of Intimate Partner Violence. Pakistan J Psychol Res [Internet]. 2012; 27(2): 279-95. Available from:

$\mathrm{http}: / /$ search.ebscohost.com/login.aspx?direct=true $\& \mathrm{db}=\mathrm{a} 9 \mathrm{~h} \&$ $\mathrm{AN}=90585362 \&$ site $=$ ehost-live \&scope $=$ site.

[9] Labrador Encinas FJ, Fernández-Velasco MR, Rincón González PP. Psychopathological characteristics of female victims of intimate partner violence. Psychol Spain [Internet]. 2011; 15(15): 102-9. Available from: https://dialnet.unirioja.es/servlet/articulo? codigo $=4027522$ \&in fo $=$ resumen\&idioma $=$ ENG.

[10] Pico-Alfonso MA, Garcia-Linares MI, Celda-Navarro N, Blasco-Ros C, Echeburúa E, Martinez M. The impact of physical, psychological, and sexual intimate male partner violence on women's mental health: depressive symptoms, posttraumatic stress disorder, state anxiety, and suicide. J Womens Health (Larchmt) [Internet]. 2006 Jun [cited 2016 Oct 16]; 15(5): 599-611. Available from: http://www.ncbi.nlm.nih.gov/pubmed/16796487. 